\title{
A human RNA helicase-like protein, HRH1, facilitates nuclear export of spliced mRNA by releasing the RNA from the spliceosome
}

\author{
Mutsuhito Ohno and Yoshiro Shimura' \\ Department of Biophysics, Faculty of Science, Kyoto University, Kyoto 606, Japan
}

Because the nuclear export of mRNA occurs only after the splicing reaction is completed, intron-containing pre-mRNA does not normally appear in the cytoplasm. As a mechanism to secure this, intron-containing RNA is retained in the nucleus via formation of the spliceosome. Therefore, the process of releasing spliced mRNA from the spliceosome after completion of splicing is an essential step for triggering the nuclear export of the spliced mRNA. In budding yeast, RNA helicase-like protein Prp22 is implicated in this process. Here we demonstrate the function of HRH1, a human protein homologous to Prp22, in mammalian cells using dominant-negative HRH1 mutants (dn-HRH1). dn-HRH1 protein stalls on the spliceosome and prevents release of the spliced RNA from the spliceosome in vitro. Expression of dn-HRH1 in mammalian cells leads to inhibition of splicing and to extensive nuclear export of unspliced pre-mRNA, probably because of the incapability of recycling spliceosome components that normally retain the pre-mRNA in the nucleus. The arginine/serine-rich domain (RS domain) of HRH1, which is missing in Prp22, confers a nuclear localization signal, and appears to facilitate the interaction of HRH1 with the spliceosome. This is the first report on a bona fide mammalian homolog of yeast Prp splicing factor, and also on a mammalian RNA helicase-like splicing factor.

[Key Words: RNA helicase; spliceosome; RNA export]

Received January 12, 1996; revised version accepted March 1, 1996.

In eukaryotes, protein coding genes are often disrupted by introns. The intron sequences are accurately removed from the primary transcripts via nuclear pre-mRNA splicing. Pre-mRNA splicing occurs within a large RNAprotein complex called spliceosome /for review, see Krainer and Maniatis 1988; Green 1991; Moore et al. 1993). The spliceosome is formed by the ordered assembly of the U1, U2, U4/U6, and U5 small nuclear ribonucleoprotein particles (snRNPs), and various non-snRNP proteins onto pre-mRNA. Following the spliceosome assembly, splicing proceeds via two sequential transesterification reactions. The first reaction (step 1) involves cleavage of the $5^{\prime}$ splice site and formation of a phosphodiester bond between the conserved guanosine at the $5^{\prime}$ end of the intron and the $2^{\prime}$ hydroxyl of the adenosine residue in the branchpoint sequence to produce the $5^{\prime}$ exon and the lariat intron- $3^{\prime}$ exon as intermediates. In the second step (step 2), the two exons are ligated and the lariat intron is excised. After both steps are completed, the spliced mRNA is released from the spliceosome and exported to the cytoplasm where the mRNA is used as a

\footnotetext{
${ }^{1}$ Corresponding author.
}

template for protein synthesis (for review, see Izaurralde and Mattaj 1995).

Because the nuclear export of mRNA occurs only after the splicing reaction is completed, intron-containing pre-mRNA does not normally appear in the cytoplasm. As a mechanism to secure this, intron-containing RNA is retained in the nucleus via formation of the spliceosome (Chang and Sharp 1989; Legrain and Rosbash 1989; Hamm and Mattaj 1990). Therefore, the process of releasing spliced mRNA from the spliceosome after completion of the splicing reaction is an essential step for triggering the nuclear export of the spliced mRNA /Company et al. 1991).

Genetic studies in budding yeast (Saccharomyces cerevisiae / have led to the identification of many genes that are required for pre-mRNA processing, termed PRP genes (for review, see Guthrie 1991; Ruby and Abelson 1991; Rymond and Rosbash 1992). Several protein splicing factors encoded by $P R P$ genes have motifs characteristic of an expanding family of putative ATP-dependent RNA helicases (Linder et al. 1989; Wassarman and Steitz 1991), which are supposed to modulate RNA-RNA basepairing interactions during the splicing process. Such proteins are mainly classified into two subfamilies, 
DEAD- and DEAH-box proteins, according to the difference in the conserved protein motifs. Three yeast DEAH-box proteins, Prp2, Prp16, and Prp22, were shown previously to function sequentially in the splicing process (Lin et al. 1987; Company et al. 1991; Schwer and Guthrie 1991). Prp2 and Prp16 are required for steps 1 and 2 of the splicing reaction, respectively, and Prp22 promotes release of the spliced mRNA from the spliceosomes.

In contrast to budding yeast, any RNA helicase-like splicing factor has not been identified in higher eukaryotes. Recently, we have identified a human RNA helicase-like factor, HRH1 (Human RNA helicase 1), which is highly homologous to $\operatorname{Prp} 22$ (Ōno et al. 1994). Expression of HRH1 in the yeast prp22 mutant could partially rescue the temperature-sensitive phenotype, suggesting that HRH1 is a human homolog of yeast Prp22 (Ono et al. 1994). Interestingly, HRHl but not Prp22 contains at its amino terminus an arginine/serine-rich domain (RS domain) which is characteristic of some metazoan splicing factors (Theissen et al. 1986; Boggs et al. 1987; Chou et al. 1987; Amrein et al. 1988; Ge et al. 1991; Krainer et al. 1991; Fu and Maniatis 1992; Zahler et al. 1992; Zamore et al. 1992). We have shown previously that HRHl can interact in vitro and in the yeast two-hybrid system with SR protein splicing factors through its RS domain (Ono et al. 1994). Although these results suggest that $\mathrm{HRHl}$ is involved in splicing-related process in mammalian cells, the function of HRH1 in mammalian cells still remains to be elucidated.

In this report we describe functional analyses of $\mathrm{HRH} 1$ in mammalian cells using dominant-negative $\mathrm{HRHI}$ mutants (dn-HRH1). Our results using an in vitro splicing system demonstrated that dn-HRHl protein stalls on the spliceosome and prevents release of the spliced RNA from the spliceosome. Expression of dn-HRHl in mammalian cells leads to inhibition of pre-mRNA splicing and to extensive nuclear export of unspliced pre-mRNA. We interpret this to mean that spliceosome components that normally retain the pre-mRNA in the nucleus cannot be recycled because of the accumulation of the stalled spliceosomes in vivo.

We also examined the functions of the RS domain of HRH1 that is missing in Prp22. Our results suggest that the RS domain functions as a nuclear localization signal (NLS) and appears to facilitate the interaction of HRHI with the spliceosome.

Our results demonstrated clearly that $\mathrm{HRHl}$ is a functional human homolog of yeast Prp22. This is the first report on a bona fide mammalian homolog of yeast Prp splicing factor, and also on a mammalian RNA helicaselike splicing factor.

\section{Results \\ Construction of HRH1 dominant-negative mutants}

To investigate the function of $\mathrm{HRHl}$ in mammalian cells, two kinds of putative dominant-negative mutants of HRHl were constructed. Figure 1 represents the motifs of the putative RNA helicase domain of HRH1 conserved among the DEAH-box family and the two mutants constructed. In the first HRH1 mutant, designated GET, the GETGSGKT motif implicated in ATP-binding activity was mutated to GETGSGET because similar mutations in other RNA helicases are shown to exert dominant-negative activity (Pause and Sonenberg 1992; C. Guthrie, pers. comm.). In the GET mutant, loss of ATP-binding activity is expected. In the second mutant, the SAT motif suggested that the coupling of ATPase activity with helicase activity was mutated to LAT, as a dominant-negative mutant of Prp2 is known to have the same mutation (Pause and Sonenberg 1992; Plumpton et al. 1994). In the LAT mutant, the ATPase activity is expected to be retained but putative helicase activity is expected to be impaired (Plumpton et al. 1994).

\section{dn-HRH1 proteins cause both inhibition of pre-mRNA splicing and nuclear export of unspliced RNA in vivo}

These mutants were transiently expressed in COS7 cells by transfection, and a luciferase reporter gene was cotransfected. This reporter gene contains the SV40 small $t$ intron in the $3^{\prime}$-untranslated region. Splicing and nuclear export of the luciferase transcript were investigated by reverse transcription PCR (RT-PCR) using primers that sandwich the intron. RNAs from both total cellular and cytoplasmic fractions were extracted from transfected COS7 cells and analyzed. To monitor the transfection efficiency, a lac $Z$ reporter gene without intron was also cotransfected. When the RNA from the total cellular fraction was examined, splicing of the luciferase reporter transcript was inhibited at least partially when the GET or the LAT mutant was expressed, whereas expression of wild-type HRH1 had essentially no effect as compared with the vector control (Fig. 2A, Luc-t, Totall. When the cytoplasmic RNA was examined, unspliced RNA, which is normally retained in the nucleus, was extensively exported to the cytoplasm in the case of both mutants (Fig. 2A, Luc-t, Cyto). Neither

Figure 1. Construction of putative dominant-negative HRHl mutants. The conserved motifs of the putative RNA helicase domain of $\mathrm{HRHI}$ are shown by single-letter amino acid code, and boxed. The lines between the conserved motifs represent less conserved amino acid sequences. The positions of the two mutations constructed are indicated. Lysine $(\mathrm{K})$ at position 594 was mutated to glutamic acid $(E)$, and serine $(S)$ at 717 to leucine (L), respectively.

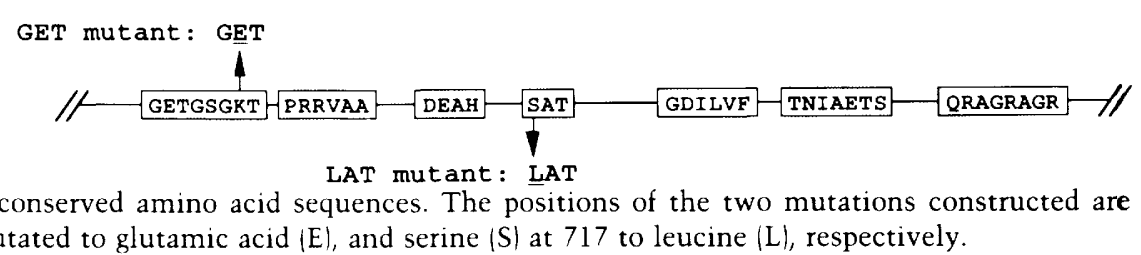



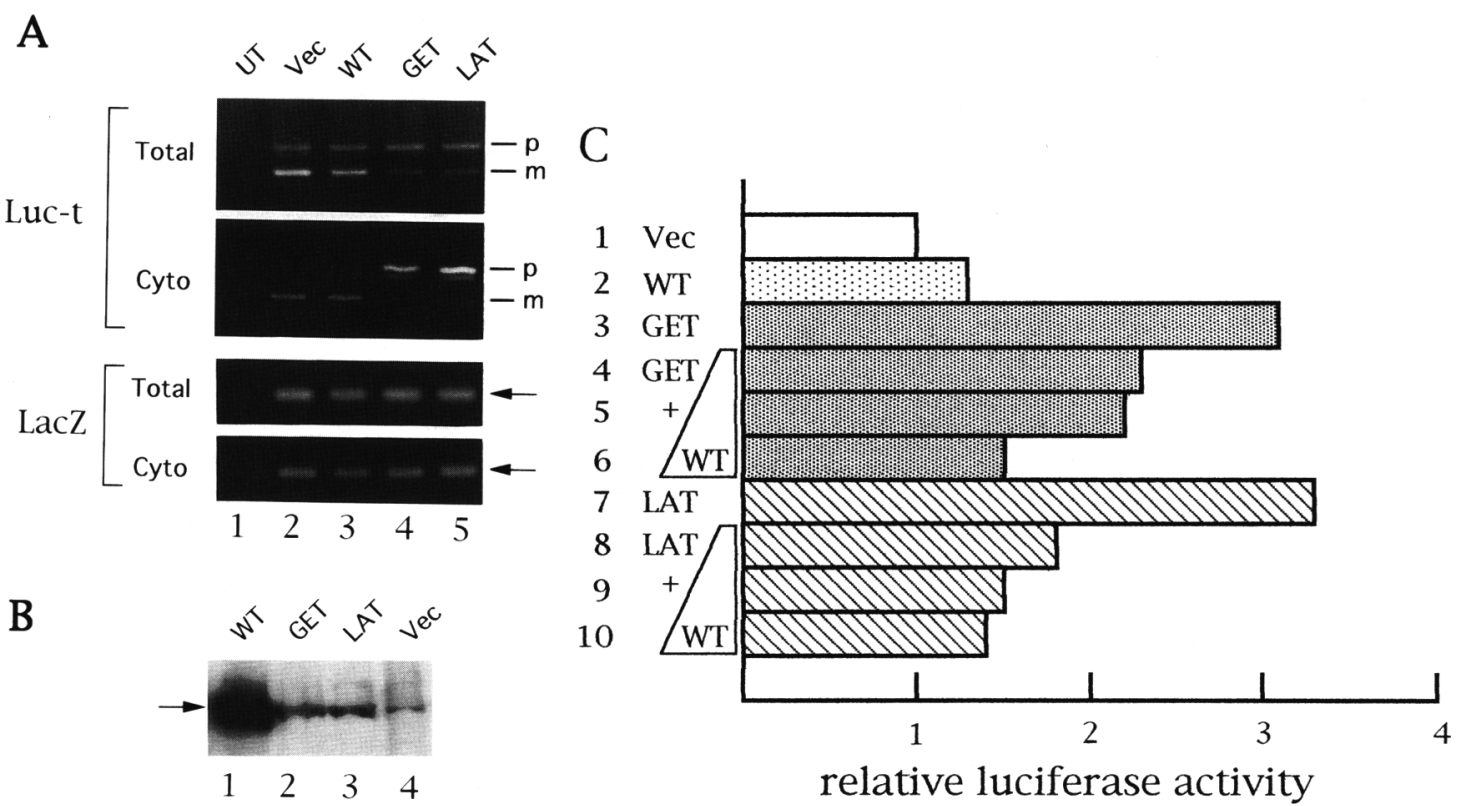

Figure 2. (A) Effect of the HRHl mutants on mRNA splicing and nuclear export in vivo. The wild-type or the mutant HRH1 proteins were expressed in COS7 cells by transfection. Two reporter genes, the luciferase gene containing the SV40 small $t$ intron in the $3^{\prime}$-untranslated region (Luc-t) and the lacZ gene without intron (LacZ), were cotransfected. Total cellular RNA (Total) or cytoplasmic RNA (Cyto) were prepared from the transfected cells and analyzed by RT-PCR using the primers specific to each reporter gene. In the case of Luc-t, $\mathrm{p}$ and $\mathrm{m}$ represent unspliced and spliced RNA products, respectively. (Lane 1) RNA from untransfected COS7 cells (UT); (lane 2) cells transfected with the expression vector pEF-BOS-T7 itself (Vec); (lane 3) wild-type HRH1 (WT); (lane 4) GET mutant; (lane 5) LAT mutant. When only the reverse transcription reaction was omitted, amplified bands were barely detected (not shown) indicating that the amplified bands are derived from RNAs. $(B)$ Expression of HRHl proteins. In an experiment similar to $A$, total protein from an equivalent number of cells transfected with different $\mathrm{HRHI}$ constructs was fractionated by $7.5 \%$ SDS-PAGE, and detected by Western blot analysis using anti-T7 epitope antibody. (Lane 1) Wild-type HRHl protein (144 kD); (lane 2) GET mutant protein (144 $\mathrm{kD})$; (lane 3) LAT mutant protein $(144 \mathrm{kD})$; (lane 4$)$ the expression vector alone for control. Note that a background band of the same mobility as the $\mathrm{HRHl}$ proteins is seen in lane $4 .|C|$ Relative luciferase activity to $\beta$-gal activity. In experiments similar to $A$, both luciferase and $\beta$-gal activities were measured, and relative luciferase activity to $\beta$-gal activity was calculated. (Line 1 ) the expression vector; (line 2) wild-type HRHl plasmid; (line 3) GET mutant plasmid; (line 4) GET mutant plus equal amount of wild type; (line 5) GET mutant plus 2.5-fold excess of wild type; (line 6) GET mutant plus fivefold excess of wild type; (line 7) LAT mutant; (line 8) LAT mutant plus equal amount of wild type; (line 9) LAT mutant plus 2.5 -fold excess of wild type; fline 10) LAT mutant plus fivefold excess of wild type. The relative luciferase activity is expressed relative to the activity of the expression vector (line 1 ) taken as 1.0 . The results were confirmed by at least three separate experiments.

production of the LacZ transcript nor its nucleocytoplasmic distribution was significantly affected (Fig. 2A), indicating that the transfection efficiency of the different constructs is comparable and that the mutants do not affect nuclear export of mRNA without introns (also see Fig. 6A, below, lanes 13-18). Moreover, the effect of the mutants is not specific to the substrate and the cell type, as similar results were obtained when the human $\beta$-globin first intron was used instead of the SV40 small $\mathrm{t}$ intron (see Fig. 6A, below, lanes 7-12) and when HeLa cells were used instead of COS7 cells (data not shown). These results suggest that the function of $\mathrm{HRHI}$ in mammalian cells is related to RNA splicing and/or RNA export.

When luciferase activity relative to $\beta$-galactocidase activity in the transfected cells was measured in the same series of experiments, a threefold increase in the activity was observed with both mutants (Fig. 2C, lines 3,7). It is most plausible that the increase of the luciferase activity is attributable to the translation of the extensively ex- ported pre-mRNA because the intron in the 3 '-untranslated region does not essentially affect the translation of the pre-mRNA. Consistently, if a luciferase reporter gene containing an intron in the $5^{\prime}$-untranslated region was used, the pre-mRNA could not have produced luciferase without splicing, and a decrease in the luciferase activity was observed (data not shown). These results argue that the RNA analysis shown above is not an artifact of nucleocytoplasmic fractionation and that majority of the pre-mRNA exported to the cytoplasm remains undegraded.

To rule out the possibility that the dn-HRHl mutants are perturbing the cellular pathway that is not intrinsic to the function of wild-type $\mathrm{HRHl}$, we examined whether excess amount of wild-type HRHl protein could overcome the effect of the mutant proteins. If increasing amounts of the wild-type HRHl plasmid were cotransfected with the fixed amount of the dn-HRHl plasmids, the dominant effect of the mutant proteins was suppressed in a dose-dependent manner (Fig. 2C). 
Five fold excess of the wild-type plasmid could almost completely suppress the effect of the mutants as judged by the relative luciferase activity (cf. lines 6 and 10 ). These results strongly suggest that the $\mathrm{dn}-\mathrm{HRH} \mathrm{l}$ proteins are competing with wild-type HRHl.

In the same series of experiments, expression of the HRHl proteins in the transfected cells was monitored by Western blot analysis using anti-T7 epitope antibody, as the expressed HRH1 proteins contain the epitope tag at their amino termini. As seen in Figure 2B, both mutant proteins are expressed much less than wild type probably because the expression vector itself contains an intron in the 5'-untranslated region (Mizushima and Nagata 1990), thereby suppressing its own expression. The band of the same mobility as the $\mathrm{HRHl}$ proteins in lane 4 is a background band attibutable to a protein in COS7 cells (also see Fig. 6B, below). Nevertheless, the mutant proteins can still cause a dramatic effect on RNA export and splicing, whereas the wild-type HRHl has no detectable effect (Fig. 2A).

\section{dn-HRH1 protein prevents release of the spliced RNA} from the spliceosome in vitro

To investigate the action of dn-HRH1 in more detail, we also used an in vitro splicing system. For further experiments we focused on the action of the LAT mutant becuase the in vivo phenotype of the GET mutant was indistinguishable from that of the LAT mutant. The LAT mutant or wild-type HRHI was expressed in COS7 cells by transfection, and whole-cell extracts were prepared from transfected cells. The extracts were added to the in vitro splicing system using a HeLa cell nuclear extract with $\delta$-crystallin pre-mRNA as a substrate $(\mathrm{Ohno}$ et al. 1987).

Figure 3A shows the analysis of the RNA products of in vitro splicing. When the extract from untransfected COS7 cells was used, splicing occurred efficiently with time (lanes 1-4), and no difference was observed if the extract from the COS7 cells expressing wild-type HRH1 was used (lanes 8-10). However, when the extract from the COS7 cells expressing the LAT mutant was used, production of the spliced RNA was partially inhibited up to approximately one-third of wild-type extract (lanes 5-7). Moreover, the amount of splicing intermediates, that is, the $5^{\prime}$ exon and the lariat intron-3' exon, increased, suggesting that both the first and the second steps of the splicing reaction are partially inhibited. More efficient splicing was observed if less of the LAT mutant extract was used (data not shown), indicating that the LAT mutant extract is inhibitory.

To see whether the formation of splicing complexes is affected by the addition of the extracts, we analyzed spliceosome formation by a native polyacrylamide gel (Konarska 1990). The same splicing reaction mixture as in Figure 3A was applied directly to a native gel and electrophoresed. Figure $3 \mathrm{~B}$ shows the autoradiograph of the gel. In the case of the extract containing wild-type $\mathrm{HRHI}$, six major different complexes (complexes I-VI), were observed (lanes 9-12). Complex V was formed rapidly, even on ice. This complex seems to correspond to the nonspecific complex $\mathrm{H}$ designated previously (Konarska 1990), because the formation of this complex is not ATP-dependent (data not shown). Four larger complexes (I-IV) and one smaller complex (VI) were observed to form in an ATP-dependent manner (data not shown). The bands corresponding to each of the complexes were excised from the gel, and the eluted RNA was examined. As shown in Figure 3C (lanes 19-36), complexes I-III are likely to be the spliceosomes because splicing intermediates, that is, $5^{\prime}$-exon and lariat intron containing $3^{\prime}$ exon, are observed, whereas complex IV seems to be a prespliceosome corresponding to the previously identified complex A (Konarska 1990). Most of the spliced RNA is not seen in the spliceosomes but is found in the smallest complex VI (lanes 34-36), which strongly suggests that the spliced RNA is rapidly released from the spliceosomes. In the case of the extract from untransfected cells, the results were indistinguishable from those of the extract from cells transfected with wild-type HRH-1 (data not shown).

In contrast, in the case of the LAT mutant extract (Fig. 3B, lanes 5-8\}, two differences are clear, namely remarkable accumulation of complex I and inhibition of complex VI formation. When the RNA products in these complexes were examined (Fig. 3C, lanes 1-18), severe inhibition of release of the spliced RNA from complex I to complex VI was observed (lanes 16-18). This is very similar to the results of in vitro splicing with the heattreated extract from the yeast temperature-sensitive prp22 mutant (Company et al. 1991). Moreover, the lariat intron is also accumulated in complex I. In this respect, it is noteworthy that the band corresponding to the debranched intron (indicated by an asterisk in Fig. $3 \mathrm{~A})$ is not observed with the LAT mutant extract although a comparable amount of lariat intron is seen, suggesting that the lariat intron is protected from the debranching activity in the nuclear extract. Stabilization of the lariat intron is also observed in the yeast prp22 mutant (Company et al. 1991). These results indicate that HRH1 is involved in release of the spliced RNA from the spliceosome in mammalian cells, as is the case with Prp22 in yeast. Although we have not addressed the question about what the functional difference is between complexes 1-II, and III, our results suggest that the largest complex I is the final spliceosome. The results obtained here are not limited to the specific pre-mRNA employed, because essentially the same results were obtained with a human $\beta$-globin pre-mRNA /data not shown).

It has been shown previously that yeast Prp 2 protein normally interacts with the spliceosome only transiently but that SAT to LAT mutation makes the protein stall on the spliceosome (Plumpton et al. 1994). To determine whether this is also the case for the LAT mutant of HRH1, we performed immunoprecipitation experiments (Fig. 4). If the $\mathrm{HRHI}$ proteins were immunoprecipitated with anti-T7 epitope antibody, some RNA products were coprecipitated. In the case of the LAT ex- 
A

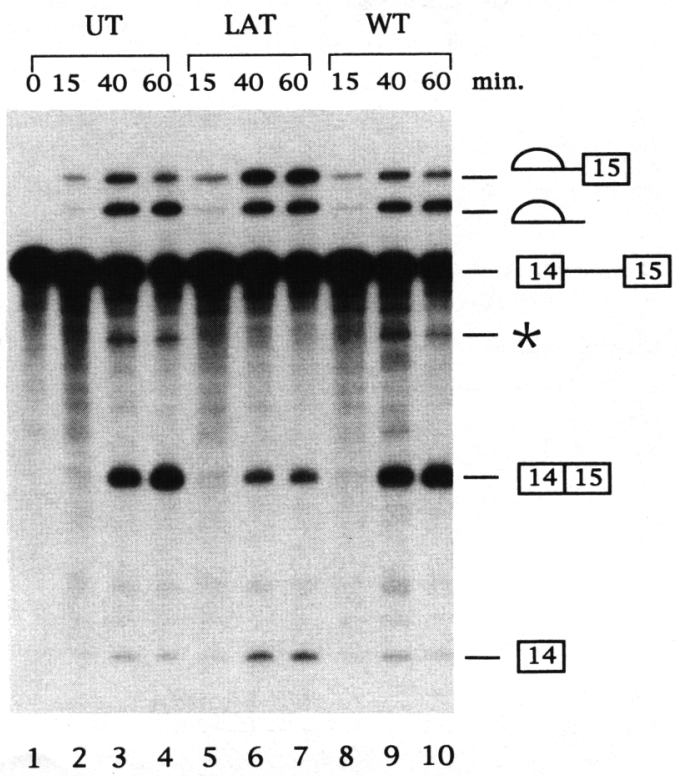

\section{B}
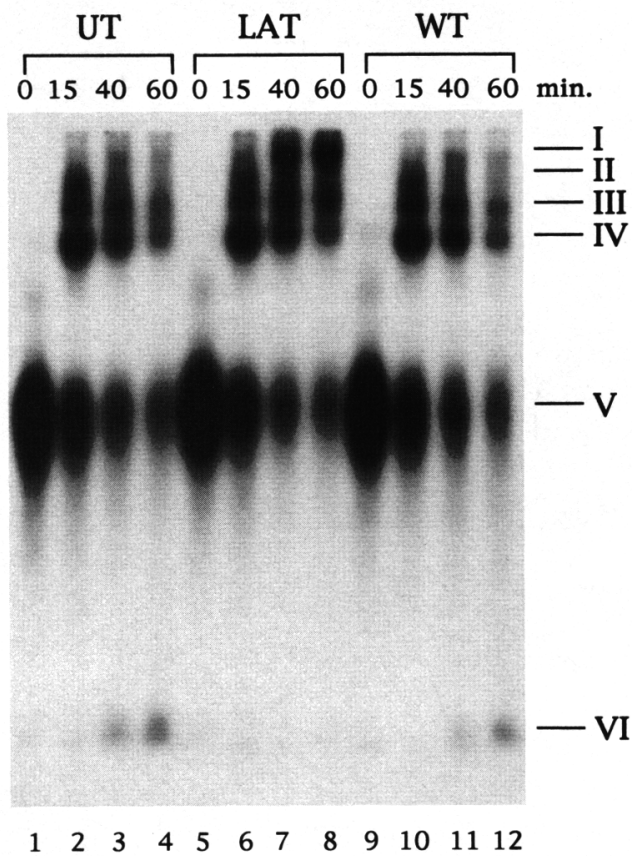

C
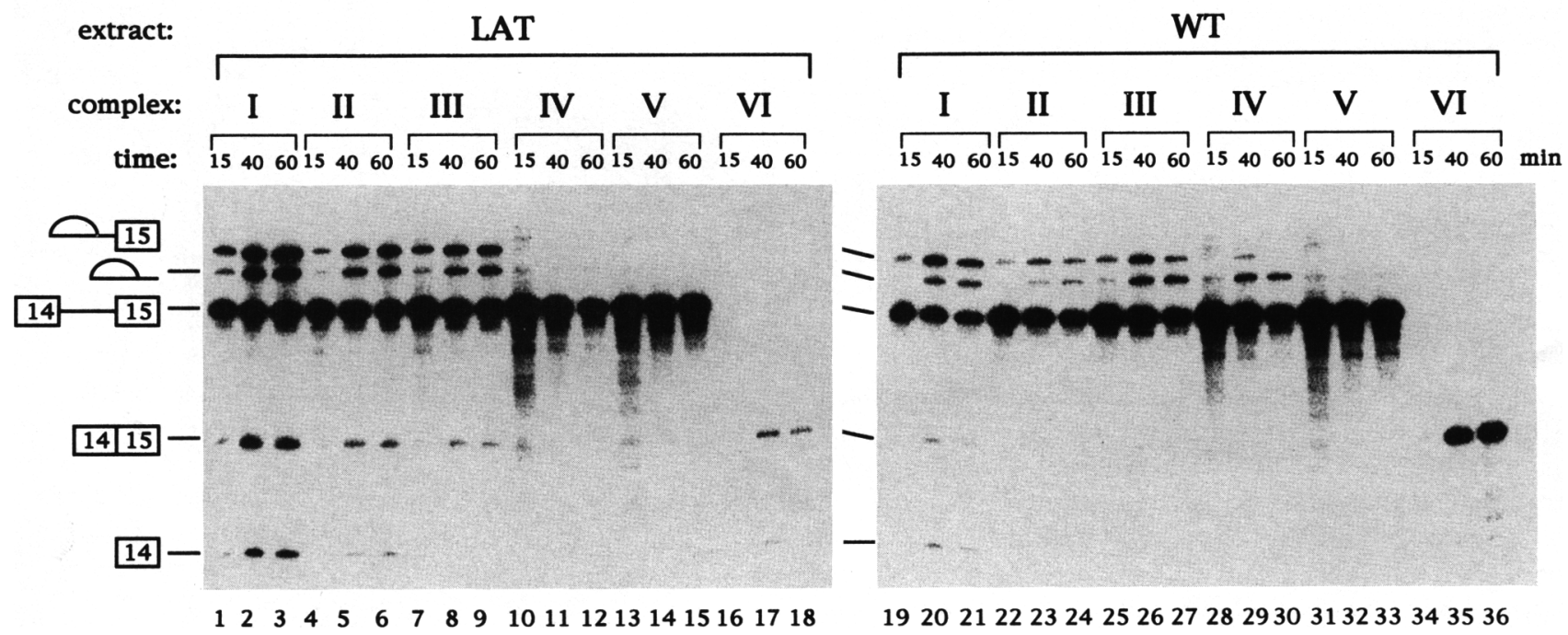

Figure 3. Effect of the LAT mutant on in vitro splicing. $|A|$ Analysis of splicing products. Extracts from COS7 cells transiently expressing HRHl proteins were added to the in vitro splicing system using a HeLa cell nuclear extract with a $\delta$-crystallin pre-mRNA. The RNA products were analyzed by $6 \%$ polyacrylamide $/ 7 \mathrm{M}$ urea gel electrophoresis and detected by autoradiography. UT (lanes $1-4$ ), extract from untransfected COS7 cells; LAT (lanes 5-7), extract from the COS7 cells expressing LAT mutant protein; WT (lanes 8-10), extract from the COS7 cells expressing wild-type HRHl protein. Structure of the RNA products are shown schematically at right. $\left.\right|^{* 1}$ The band corresponds to the debranched intron. $(B)$ Analysis of splicing complexes. Splicing complexes from the same reaction mixtures as in $A$ were fractionated by a native $3.75 \%$ polyacrylamide gel (Konarska 1990) and autoradiographed. (C) Analysis of the RNA products in the splicing complexes. Each band in $B$ was excised from the gel, and the eluted RNA was analyzed.

tract, the splicing intermediates, the lariat intron, and the spliced RNA are efficiently precipitated (lanes 5,7 ). These precipitated RNAs are identical to the RNA products in the stalled spliceosome (see Fig. 3C, lanes 1-3). In contrast, in the case of the wild type, RNA products are barely precipitated specifically with the antibody. These results strongly suggest that wild-type $\mathrm{HRH}$ targets to the spliceosome only transiently, whereas the LAT mutant protein is stably bound to the final spliceosome without releasing the spliced RNA. It is highly likely 


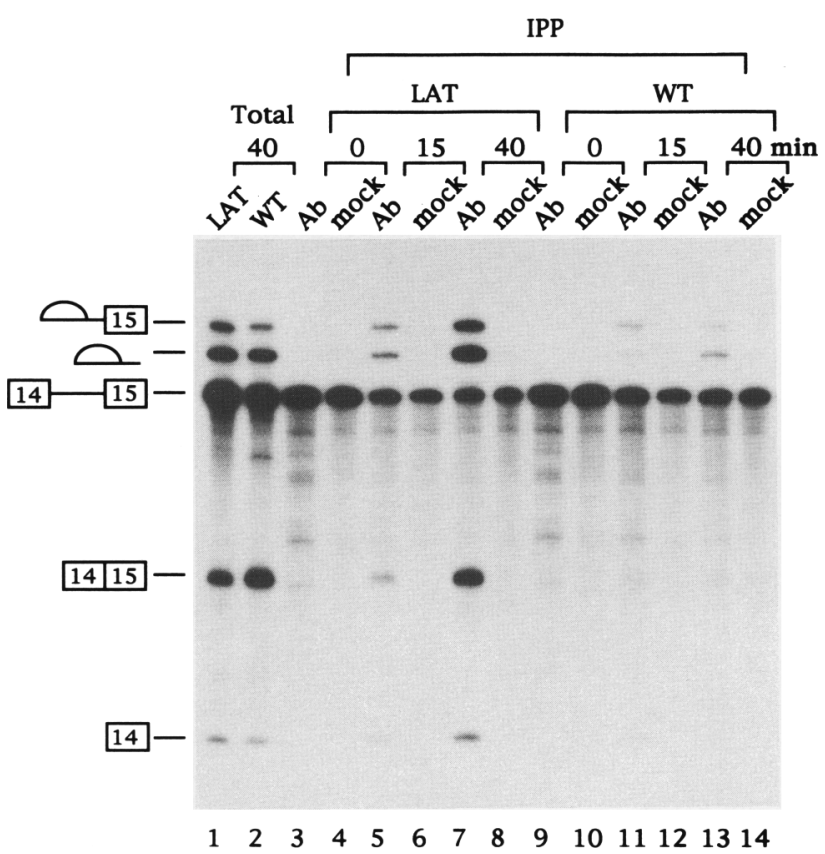

Figure 4. Immunoprecipitation analysis of HRHl proteins. $\mathrm{HRH} 1$ proteins in the in vitro splicing reaction mixture in Fig. 3 were immunoprecipitated by anti-T7 epitope antibody bound protein A-Sepharose, and coprecipitated RNA was analyzed. In the case of mock precipitation, normal mouse IgG-bound protein A-Sepharose was used. In lanes 1 and 2, total RNA products from a 40-min reaction are shown as markers.

that the LAT mutant protein competes with the wildtype HRHl for interaction with the spliceosome.

\section{Functions of the RS domain of HRH1}

HRH1 possesses an RS domain in the amino-terminal region (Ono et al. 1994), which is characteristic of some metazoan splicing factors (Theissen et al. 1986; Boggs et al. 1987; Chou et al. 1987; Amrein et al. 1988; Ge et al. 1991; Krainer et al. 1991; Fu and Maniatis 1992; Zahler et al. 1992; Zamore et al. 1992). Because such a domain is completely missing in yeast Prp22, we suppose this domain may have a specific function in adaptation to the evolved splicing system of higher eukaryotes. Because it was shown previously that the RS domains of Drosophila splicing regulators such as $\mathrm{Su}\left(\mathrm{w}^{\mathrm{a}}\right)$ and Tra can act as a nuclear/speckle localization signal ( $\mathrm{Li}$ and Bingham 1991), we first examined if this was also the case for the RS domain of HRHI.

When epitope-tagged wild-type HRH1 was transiently expressed in HeLa cells, the protein was localized to the nucleoplasm and nuclear speckles as judged by indirect immunofluorescence using anti- $\mathrm{T} 7$ epitope antibody (Fig. 5, top panel). In some cells, the speckled pattern was not clear (not shown). This speckled pattern looks very similar to the localization of some splicing factors including SC-35 (Fig. 5, bottom panel) (Fu and Maniatis 1992). When the amino-terminal region containing the
RS domain was deleted, the protein was localized primarily to the cytoplasm (Fig. 5, second panel), although some portion of the protein appears to have entered the nucleus (excluded from nucleoli). When the RS domain was replaced by the NLS from the SV40 T antigen, the protein could efficiently enter the nucleus; however, no speckled pattern was observed (Fig. 5, third panel). These results strongly suggest that at least one of the functions of the RS domain of HRH1 is to provide a nuclear/ speckle localization signal, as is the case with the Drosophila splicing regulators (Li and Bingham 1991), although HRHl without the domain can enter the nucleus, albeit inefficiently.

As we described, the LAT mutant has strong dominant-negative activity both in vivo and in vitro. Next we examined whether the deletion of the RS domain from the LAT mutant protein affects its dominant-negative activity in vivo and in vitro. The in vivo results are shown in Figure 6A. When the RS domain of the LAT mutant was deleted (LAT $\Delta$ RS) or when the domain was replaced by the NLS from SV40 T antigen (LAT $\Delta$ RS NLSI, the dominant-negative activity in vivo was impaired, if not completely, as judged by inhibition of splic-

\section{Phase Fluorescein}

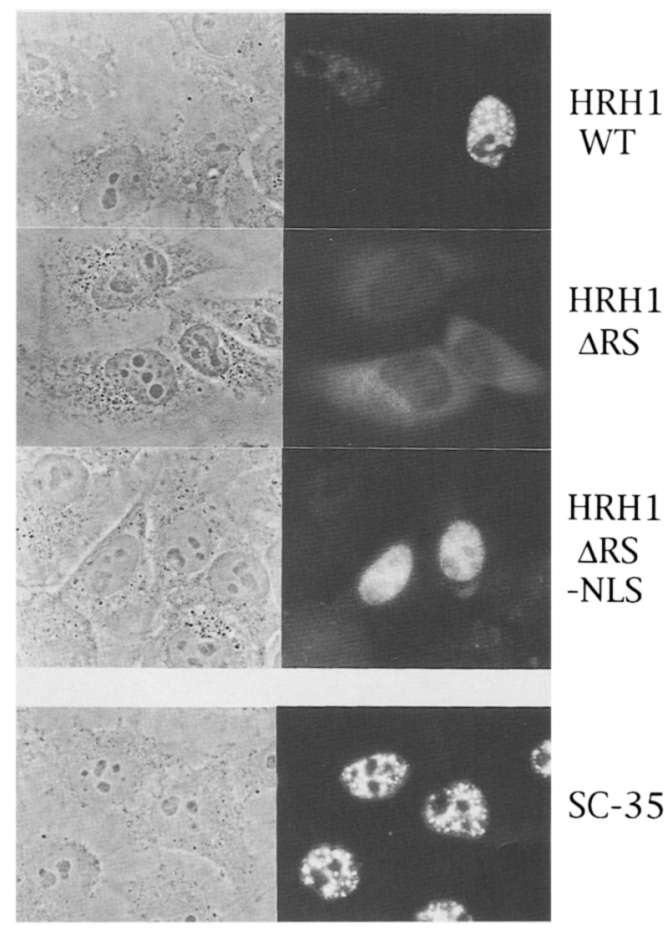

Figure 5. Localization of HRHl proteins in the cell. HeLa cells were transfected by plasmids expressing various epitope-tagged $\mathrm{HRHl}$ proteins. After $24 \mathrm{hr}$, the cells were fixed and stained by either anti-SC-35 monoclonal antibody (Fu and Maniatis 1992) (bottom panell or anti-T7 epitope monoclonal antibody (top three panels). (Top panel) Wild-type HRH1 (HRH1WT); (second panell HRH1 in which the RS domain was deleted (HRHI $\Delta$ RS); (third panel) HRH1 in which the RS domain was replaced by SV40 T nuclear localization signal (HRHl $\Delta$ RS-NLS). 
A
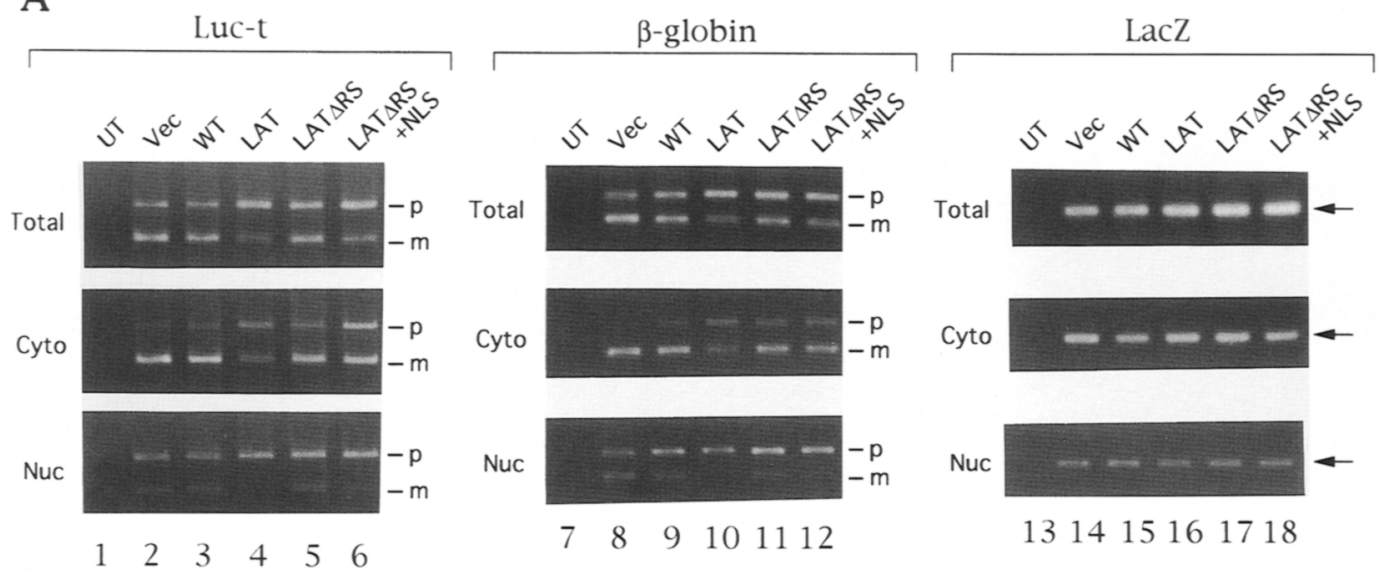

B

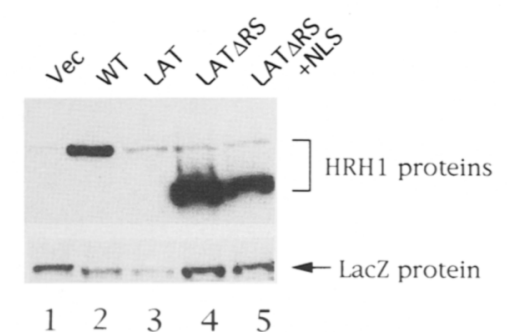

Figure 6. (A) Effect of deletion of the RS domain in the LAT mutant on mRNA splicing and nuclear export in vivo. Transfection and RNA analysis experiments similar to the one in Fig. 2A were performed using various HRH1 constructs. Here, the third reporter gene containing the first intron of the human $\beta$-globin gene was also cotransfected, and RNAs from the nuclear fractions (Nuc) were also analyzed. (LAT $\triangle$ RS) the RS domain was deleted; (LATJRS + NLS) the RS domain was replaced by the NLS from SV40 T antigen. (B) Expression of $\mathrm{HRHl}$ proteins. In an experiment similar to the one in $A$, expression of HRHl proteins and LacZ protein was detected by Western blot analysis using anti-T7 epitope antibody and anti- $\beta$-gal antibody, respectively. (Lane 1 ) Control (the expression vector); (lane 2) wild-type HRHI protein (144 kD); (lane 3) LAT mutant protein (144 kD); (lane 4) LAT $\mathrm{RS}$ protein (130 kD); (lane 5) LAT $\Delta$ RS + NLS protein $(132 \mathrm{kD}$ ). Note that background bands of the same mobility as the wild-type and LAT proteins are seen in lanes 1,4 , and 5 .

ing and cytoplasmic appearance of pre-mRNA of the reporter genes containing the SV40 small $t$ intron (cf. lanes $2-6$ ) or the human $\beta$-globin intron (cf. lanes $8-12$ ). The dominant-negative activity is somewhat stronger in LAT $\Delta$ RS-NLS than LAT $\Delta$ RS at least in the case of the luciferase reporter gene (cf. lanes 5 and 6), probably because the protein can enter the nucleus more efficiently. Consistent with this are the in vitro results shown in Figure 7A. LAT $\Delta$ RS protein exerts dominant-negative activity in vitro only weakly (compare the accumulation of complex I for LAT, wild-type and LAT- $\Delta R S$ ). When immunoprecipitation experiments as in Figure 4 were performed with LAT $\Delta$ RS extract, the amount of the precipitated RNA products was somewhat larger than for wild-type extract but much less than LAT mutant extract (data not shown). These results suggest that the RS domain is important, if not essential, for the dominantnegative activity of the LAT mutant. Considering that the interaction with the spliceosome is a prerequisite for the dominant-negative activity of the LAT mutant, the RS domain of HRHI appears to be important for the protein to interact with the spliceosome.

The dominant-negative activity of LAT $\Delta$ RS in vitro and LATARS-NLS in vivo is much weaker than that of the LAT mutant. This is neither because LAT $\Delta R S$ and LAT $\Delta$ RS-NLS proteins are expressed poorly in the cells nor because the proteins are unstable under the in vitro splicing conditions. On the contrary, the $\Delta R S$ proteins are expressed much better than LAT protein in the cells (Fig. 6B) and are very stable during in vitro splicing reactions (Fig. 7B). It should be emphasized that the $\Delta$ RS proteins are present in much greater amounts than the LAT protein, but still cause only a very weak effect. In the in vitro experiments, when the LAT $\Delta$ RS extract was diluted with extract from untransfected cells so that the amount of LAT $\Delta$ RS protein became comparable to that of LAT protein in the LAT extract, the diluted extract could not exert detectable dominant-negative activity in vitro (data not shown). These results strongly suggest that the RS domain of $\mathrm{HRHl}$ is very important for its function as is the case for other splicing factors with RS domains (Zamore et al. 1992; Cáceres and Krainer 1993; Zuo and Manley 1993). It is unlikely that deletion of the RS domain affects overall protein conformation, leading to weak dominant-negative activity, as $\Delta R S$ and $\Delta R S$ NLS proteins in the wild-type HRH1 context can com- 
A
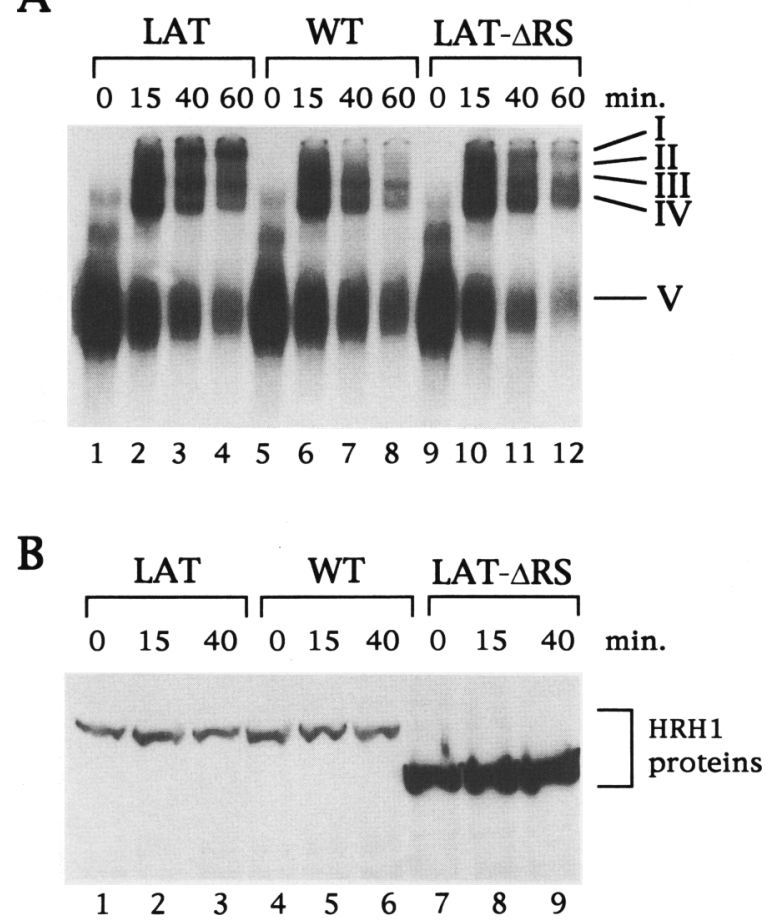

Figure 7. (A) Effect of the deletion of the RS domain in the LAT mutant on the dominant-negative activity in vitro. The effect of the LAT mutant protein in which the RS domain was deleted (LAT- $\Delta$ RS) on the formation of the splicing complexes was examined as in Fig. 3B. Only complexes I-V are shown. $|B|$ Stability of $\mathrm{HRH} 1$ proteins in vitro. The same in vitro splicing mixtures as in $A$ were analyzed by Western blotting using anti$\mathrm{T} 7$ epitope antibody.

plement the yeast prp22 mutation to the same extent as the wild-type HRHl (Ono et al. 1994).

\section{Discussion}

Possible link between in vitro and in vivo phenotypes caused by dn-HRH1

Although our results indicate that $\mathrm{HRH} 1$ is functionally equivalent to yeast $\operatorname{Prp} 22$, there is some difference between the phenotypes caused by the mutations. It was shown previously that the heat-treated extract from the yeast temperature-sensitive prp22 mutant has normal splicing activity in terms of the production of the spliced RNA but is defective in release of the spliced RNA from the spliceosome (Company et al. 1991). In contrast, the LAT mutant not only prevents release of the spliced RNA from the spliceosome, but also partially inhibits the splicing reactions in vitro (Fig. 3A). It is unlikely that the LAT mutant protein directly inhibits the splicing, as the inhibitory effect was observed only at a late stage of the time course, that is, neither the splicing reaction nor spliceosome formation is affected by the LAT mutant protein after 15 min (Fig. 3, A, cf. lanes 2, 5, and 8 with $B$, lanes 2, 6, and 10). In contrast, partial inhibition of splicing is clear after $40 \mathrm{~min}$ with the LAT extract, and the splicing reactions do not seem to proceed further (Fig. 3A, lanes 6,7). We interpret these results to mean that in our mammalian in vitro splicing system, some splicing factors can recycle, and that splicing with the LAT extract is less efficient because of prevention of recycling of the factors. In contrast, in the yeast in vitro splicing system, there may be essentially no recycling of splicing factors.

Expression of the dn-HRHl mutants in mammalian cells leads to inhibition of pre-mRNA splicing and to extensive nuclear export of the unspliced RNA. Our in vitro results suggest that in the case of the LAT extract, stalled spliceosomes are accumulated and that the splicing factors in the spliceosomes cannot take part in the next round of splicing. It is likely that similar events occur in vivo. We speculate that some splicing factors that normally retain unspliced RNA in the nucleus are eventually sequestered (at least partially) in this way and that the unspliced RNAs are exported to the cytoplasm as if they did not contain introns. A similar recycling model was proposed previously in yeast to explain the in vivo splicing defect of the yeast prp22 mutant (Company et al. 1991; Ruby and Abelson 1991). It has been also shown in budding yeast that some temperature-sensitive prp mutations lead to nuclear export of pre-mRNAs at the restrictive temperature (Legrain and Rosbash 1989).

The in vivo phenotype caused by dn-HRHl is reminiscent of the effects caused by the Rev protein of HIV-1 and other related virus proteins (for review, see Cullen 1992). Rev protein also causes nuclear export of unspliced RNA, but its mode of action is different. Rev acts only on the pre-mRNAs containing a Rev-binding sequence, the so-called Rev responsive element (RRE), whereas dnHRHl proteins can act on pre-mRNAs devoid of any specific element. Recently, it has been shown that Rev is directly involved in the RNA export process (Fischer et al. 19951.

\section{Functions of the RS domain of HRH1}

Our results in this paper indicate that at least one of the functions of the RS domain of HRH1 is as a nuclear/ speckle localization signal, although $\mathrm{HRH}$ without the domain can enter the nucleus, albeit inefficiently. Considering that yeast Prp22 protein does not have the RS domain, it is of interest to investigate where the NLS is in the Prp22 protein.

Our results also strongly suggest that the LAT mutant protein competes with wild-type HRHl for interaction with the spliceosome and that the RS domain facilitates the interaction. The RS domains have been implicated in specific protein-protein interactions ( $\mathrm{Wu}$ and Maniatis 1993; Amrein et al. 1994; Kohtz et al. 1994). We have shown previously that $\mathrm{HRHI}$ can interact in vitro and in the yeast two-hybrid system with SR protein splicing factors through its RS domain (Ono et al. 1994). Taken together, the interaction between HRHI and the spliceosome may be mediated by the SR proteins in the spliceosome through RS domains. The RS domains appear to be characteristic of metazoan splicing factors, but a canonical RS domain has not been identified in yeast so far. 
Therefore, it is interesting to suppose that HRHl acquired an extra RS domain to function more efficiently in the more highly evolved splicing system of higher eukaryotes.

\section{A RNA helicase-like protein that links $m R N A$ splicing and nuclear export}

The process of releasing the spliced RNA from the spliceosome is a prerequisite for initiating nuclear export of the RNA (Chang and Sharp 1989; Legrain and Rosbash 1989; Hamm and Mattaj 1990; Company et al. 1991). Considering that most nuclear genes are disrupted by introns in mammalian cells, the function of $\mathrm{HRHl}$ is much more versatile than Prp22 in yeast cells, where only limited number of genes contain introns. $\mathrm{HRHI}$ (and Prp22 in yeast) is a protein that links mRNA splicing and nuclear export, and therefore, may be able to interact with both splicing and export factors. SR proteins must be plausible candidates for these splicing factors. Moreover, there is an intriguing possibility that HRH1 may interact with export factors and bring them to the final spliceosome, so that the next mRNA export step becomes more efficient. In this respect, it is of interest to screen proteins that interact with $\mathrm{HRH}$. Such experiments are currently under way in our laboratory.

\section{Significance of RNA helicase-like splicing factors in mammalian cells}

In this report we were able to demonstrate for the first time that an RNA helicase-like protein is involved in the splicing-related process in mammalian cells as is the case in yeast cells. In budding yeast, several RNA helicase-like splicing factors have already been identified (for review, see Wassarman and Steitz 1991; Fuller-Pace 1994). It is possible to assume that more RNA helicaselike splicing factors will be identified in mammalian cells, as the importance of regulation of RNA-RNA interactions in the spliceosome must be conserved through evolution. However, there is a controversy about whether these proteins are really acting as RNA helicases. None of the yeast RNA helicase-like splicing factors have been shown to have RNA helicase activity so far, although some of them have been shown to have RNA-dependent ATPase activity (Schwer and Guthrie 1991; Kim et al. 1992/. In this respect, the ATPase/RNA helicase activities of $\mathrm{HRH} 1$ as well as its specific RNA substrate in the spliceosome remain to be investigated.

\section{Materials and methods \\ Transfection and measurement of luciferase and $\beta-g a l$ activities}

COS7 cells were grown in $35-\mathrm{mm}$ dishes to $50 \%-80 \%$ confluence. Transfection was performed using Lipofectamine (GIBCO/BRL) according to the protocol recommended by the manufacturer. In typical experiments, $0.3-0.7 \mu \mathrm{g}$ of HRH1-expressing plasmid and $0.1-0.3 \mu \mathrm{g}$ of each reporter plasmid were transfected. Luciferase activity of the transfected cells was measured by using the luciferase assay kit from Promega.

\section{Analysis of RNAs}

Total, cytoplasmic, and nuclear RNAs were isolated as described (Maniatis et al. 1982; Chang and Sharp 1989). Reverse transcription PCR (RT-PCR) was performed using the RNA PCR kit (Takara Biochemical). The number of the PCR cycles was minimized so that the amplification was in the linear range. Specific primers to amplify each reporter transcript and the size of the amplified fragments are as follows. Luc-t, $5^{\prime}$ GTAATACTGCGATGAGTGGCAG-3' and 5'-CATTCATCAGTTCCATAGGTTGG-3', unspliced, 291 bp, spliced, 225 bp; LacZ, 5' -TCACACTACGTCTGAACGTCG-3' and 5' $5^{\prime}$ TGTTCTGCTTCATCAGCAGG-3', 282 bp; $\beta$-globin, 5'-CTGACAAACTGTGTTCACTAG-3' and 5'-CACGTGCAGCTTGTCACAGTG-3', unspliced, $467 \mathrm{bp}$, spliced, $336 \mathrm{bp}$.

\section{Preparation of whole-cell extracts from transfected COS7} cells

Transfected COS7 cells were harvested with a rubber policeman and washed three times with PBS. The cells were resuspended in buffer $\mathrm{D}^{\prime} \mathrm{K} 100$ |20 mM HEPES-NaOH (pH 7.9), 0.2 mM EDTA, $100 \mathrm{~mm} \mathrm{KCl}, 1 \mathrm{~mm}$ DTT, $0.2 \mathrm{mM}$ APMSF] and disrupted by glass beads (425-600 microns, Sigma) by vortexing. The lysate was collected in a sample tube and spun at $15,000 \mathrm{rpm}$ for $20 \mathrm{~min}$ at $4^{\circ} \mathrm{C}$. The supernatant was collected, and the protein concentration was adjusted to $14-20 \mathrm{mg} / \mathrm{ml}$ as judged by a protein assay kit (Bio-Rad).

In vitro splicing and analysis of the splicing complex formation

The in vitro splicing reaction was performed as described previously (Ohno et al. 1987). The typical $10-\mu$ l reaction mixture contained $1 \mu \mathrm{l}$ of HeLa cell nuclear extract and $5 \mu \mathrm{l}$ of COS7 cell extract as well as other cofactors necessary for the reaction. Native-gel analysis of the splicing complexes was performed according to the protocol described previously by Konarska (1990).

\section{Immunoprecipitation}

The in vitro splicing reaction was performed in $10 \mu l$, and the reaction was terminated by putting the reaction mixture on ice. Heparin $(50 \mu \mathrm{g})$ and anti-T7 epitope antibody $(6 \mu \mathrm{g}$ of purified IgG, Novagen/ were added, and the mixture was incubated on ice for $\mathrm{l}$ hr. Ten microliters of protein A-Sepharose (PAS) equilibrated with buffer E [12 mM HEPES-NaOH (pH 7.9), $0.12 \mathrm{~mm}$ EDTA, $60 \mathrm{mM} \mathrm{KCl}, 1 \mathrm{~mm}$ DTT, $0.2 \mathrm{~mm}$ APMSF] was added, and the mixture was incubated at $4^{\circ} \mathrm{C}$ for $1 \mathrm{hr}$ on a rotating platform. After the incubation, PAS was spun down and washed four times with $500 \mu \mathrm{l}$ of buffer E. The RNA products that coprecipitated with the final pellet were isolated by proteinase $\mathrm{K}$ treatment and phenol/chroloform extraction followed by ethanol precipitation, and analyzed.

\section{Immunofluorescence}

Immunofluorescence was performed essentially as described previously (Kataoka et al. 1994) using anti-T7 antibody (Novagen) and FITC-labeled affinity-purified anti-mouse IgG (DAKO). 


\section{Plasmid constructions}

The expression vector pEF-BOS-T7 was constructed by inserting two preannealed oligonucleotides $15^{\prime}$-CTAGCCATGGCCAGCATGACTGGTGGACAGCAAATGGGTCGGATCC-3' and 5'-CTAGGGATCCGACCCATTTGCTGTCCACCAGTCATGCTGGCCATGG-3'), corresponding to T7 epitope, into the $\mathrm{XbaI}$ site of pEF-BOS (Mizushima and Nagata 1990). The full-length wild-type HRHI cDNA was inserted in-frame at the BamHI site of pEF-BOS-T7. GET and LAT mutant plasmids were constructed by oligonucleotide mutagenesis using wildtype HRHl plasmid. Deletion of the amnio-terminal region containing the RS domain (amino acid residues 1-249) was carried out by PCR amplification of the corresponding fragment. Replacement of the RS domain with the NLS of SV40 T was done by inserting oligonucleotides corresponding to the NLS (PKKKRKV, 5'-CCAAAGAAGAAGAGAAAGGTC-3' and the complementary oligonucleotide) at the deletion point. The luciferase reporter gene with SV40 $t$ intron (Luc- $t$ ) was purchased from Promega (pGL2-Control Vector). The lac $Z$ reporter gene without intron was from Pharmacia ( $\mathrm{pCH} 1 \mathrm{lO})$. The human $\beta$-globin reporter gene was constructed by inserting the HindIIIBamHI fragment from pSP64-H $\beta \Delta 6$ (Krainer et al. 1991) into the same sites of $\mathrm{pRc} / \mathrm{CMV}$ (Invitrogen).

\section{Acknowledgments}

We thank A. Mayeda, K. Inoue, and K. Hoshipima for helpful advice and comments on this manuscript. This work was supported by grants from the Ministry of Education, Science, Sports, and Culture, Japan.

The publication costs of this article were defrayed in part by payment of page charges. This article must therefore be hereby marked "advertisement" in accordance with 18 USC section 1734 solely to indicate this fact.

\section{References}

Amrein, H, M. Gorman, and R. Nöthiger. 1988. The sex determining gene tra- 2 of Drosophila encodes a putative RNA binding protein. Cell 55: 1025-1035.

Amrein, H., M.L. Hedley, and T. Maniatis. 1994. The role of specific protein-RNA and protein-protein interactions in positive and negative control of pre-mRNA splicing by transformer 2. Cell 76: 735-746.

Boggs, R.T., P. Gregor, S. Idriss, J.M. Belote, and M. McKeown. 1987. Regulation of sexual differentiation in D. malanogaster via alternative splicing of RNA from the transformer gene. Cell 50: 739-747.

Cáceres, J.F., and A.R. Krainer. 1993. Functional analysis of premRNA splicing factor SF2/ASF structural domains. EMBO $\%$ 12: 4715-4726.

Chang, D.D. and P.A. Sharp. 1989. Regulation by HIV Rev depends upon recognition of splice sites. Cell 59: 789-795.

Chou, T. B., Z. Zachar, and P.M. Bingham. 1987. Developmental expression of a regulatory gene is programmed at the level of splicing. EMBO I. 6: 4095-4104.

Company, M., J. Arenas, and J. Abelson. 1991. Requirement of the RNA helicase-like protein PRP22 for the release of messenger RNA from spliceosomes. Nature 349: 487-493.

Cullen, B.R. 1992. Mechanism of action of regulatory proteins encoded by complex retroviruses. Microbiol. Rev. 56: 375394.

Fischer, U., J. Huber, W.C. Boelens, I.W. Mattaj, and R. Lührmann. 1995. The HIV-1 Rev activation domain is a nuclear export signal that accesses an export pathway used by specific cellular RNAs. Cell 82: 475-483.

$\mathrm{Fu}, \mathrm{X}$-D. and T. Maniatis. 1992. Isolation of a complementary DNA that encodes the mammalian splicing factor SC35. Science 256: 535-538.

Fuller-Pace, F.V. 1994. RNA helicases: Modulators of RNA structure. Trends Cell Biol. 4: 271-274.

Ge, H., P. Zuo, and J.L. Manley. 1991. Primary structure of the human splicing factor ASF reveals similarities with Drosophila regulators. Cell 66: 373-382.

Green, M.R. 1991. Biochemical mechanisms of constitutive and regulated pre-mRNA splicing. Annu. Rev. Cell Biol. 7: 559599

Guthrie, C. 1991. Messenger RNA splicing in yeast: Clues to why the spliceosome is a ribonucleoprotein. Science 253: 157-163.

Hamm, J. and I.W. Mattaj. 1990. Monomethylated cap structures facilitate RNA export from the nucleus. Cell 63: 109118.

Izaurralde, E. and I.W. Mattaj. 1995. RNA export. Cell 81: 153158.

Kataoka, N., M. Ohno, K. Kangawa, Y. Tokoro, and Y. Shimura. 1994. Cloning of a complementary DNA encoding an 80 kilodalton nuclear cap binding protein. Nucleic Acids Res. 22: 3861-3865.

Kim, S.-H., J. Smith, A. Claude, and R.-J. Lin. 1992. The purified yeast pre-mRNA splicing factor PRP2 is an RNA-dependent NTPase. EMBO /. 11:2319-2326.

Kohtz, J.D., S.F. Jamison, C.L. Will, P. Zuo, R. Lührmann, M.A. Garcia-Blanco, and J.L. Manley. 1994. Protein-protein interactions and $5^{\prime}$-splice-site recognition in mammalian mRNA precursors. Nature 368: 119-124.

Konarska, M.M. 1990. Analysis of splicing complexes and small nuclear ribonucleoprotein particles by native gel electrophoresis. In Methods in enzymology (eds. J. Abelson and J. Dahlbergl, Vol. 181B, pp, 442-453. Academic Press, New York, NY.

Krainer, A.R. and T. Maniatis. 1988. RNA splicing. In Frontiers in molecular biology: Transcription and splicing /ed. B.D. Hames and D.M. Glover), pp. 131-206. IRL Press, Oxford, UK.

Krainer, A.R., A. Mayeda, D. Kozak, and G. Binns. 1991. Functional expression of cloned human splicing factor SF2: Homology to RNA binding proteins, UI 70K, and Drosophila splicing regulators. Cell 66: 383-394.

Legrain, P. and M. Rosbash. 1989. Some cis- and trans-acting mutants for splicing target pre-mRNA to the cytoplasm. Cell 57: 573-583.

Li, H. and P.M. Bingham. 1991. Arginine/serine-rich domains of the su|wal and tra RNA processing regulators target proteins to a subnuclear compartment implicated in splicing. Cell 67: 335-342.

Lin, R.-J., A.J. Rustig, and J. Abelson. 1987. Splicing of yeast nuclear pre-mRNA in vitro requires a functional $40 \mathrm{~S}$ splicensome and several extrinsic factors. Genes \& Dev. 1: 7-18.

Linder, P, P. Lasko, P. Leroy, P. Nielsen, K. Nishi, I. Schinier, and P. Slonimski. 1989. Birth of J-E-A-D box. Nature 337: $121-122$.

Maniatis, T., E.F. Fritsch, and J. Sambrook. 1982. Molecular cloning: A Laboratory Manual. Cold Spring Harbor Laboratory, Cold Spring Harbor, New York.

Mizushima, S. and S. Nagata. 1990. pEF-BOS, a powerful mammalian expression vector. Nucleic Acids Res. 18: 5322.

Moore, M.I., C.C. Query, and P.A. Sharp. 1992. Splicing of precursors to messenger RNAs by the spliceosome. In The RNA world (ed. R.F. Gesteland and J.F. Atkinsl, pp. 303-358. Cold 
Spring Harbor Laboratory Press, Cold Spring Harbor, NY.

Ohno, M., H. Sakamoto, and Y. Shimura. 1987. Preferential excision of the 5' proximal intron from mRNA precursors with two introns as mediated by the cap structure. Proc. Natl. Acad. Sci. 84: 5187-5191.

Ono, Y., M. Ohno, and Y. Shimura. 1994. Identification of a putative RNA helicase (HRH1), a human homolog of yeast Prp22. Mol. Cell. Biol. 14: 7611-7620.

Pause, A. and N. Sonenberg. 1992. Mutational analysis of a DEAD box RNA helicase: The mammalian translation initiation factor eIF-4A. EMBO I. 11: 2643-2654.

Plumpton, M., M. McGarvey, and J.D. Beggs. 1994. A dominant negative mutation in the conserved RNA helicase motif "SAT" causes splicing factor PRP2 to stall in spliceosomes. EMBO J. 13: 879-887.

Ruby, S.W. and J. Abelson. 1991. Pre-mRNA splicing in yeast. Trends Genet. 7: 79-85.

Rymond, B.C. and M. Rosbash. 1992. Yeast pre-mRNA splicing. In The molecular and cellular biology of the yeast Saccharomyces: Gene expression (ed. J.R. Broach, J.R. Pringle, and E.W. Jones), pp. 143-192. Cold Spring Harbor Laboratory Press, Cold Spring Harbor, NY.

Schwer, B. and C. Guthrie. 1991. PRP16 is an RNA-dependent ATPase that interacts transiently with the spliceosome. $\mathrm{Na}$. ture 349: 494-499.

Theissen, H., M. Etzerodt, R. Reuter, C. Schneider, R. Lottspeich, P. Argos, R. Lührmann, and L. Philipson. 1986. Cloning of the human cDNA for the UI RNA-associated $70 \mathrm{~K}$ protein. EMBO /. 5: 3209-3217.

Wassarman, D.A. and J.A. Steitz. 1991. Alive with DEAD proteins. Nature 349: 463-464.

Wu, J.Y., and T. Maniatis. 1993. Specific interactions between proteins implicated in splicesite selection and regulated alternative splicing. Cell 75: 1061-1070.

Zahler, A.M., W.S. Lane, J.A. Stolk, and M.B. Roth. 1992. SR proteins: A conserved family of pre-mRNA splicing factors. Genes \& Dev. 6: 837-847.

Zamore, P.D., J.G. Patton, and M.R. Green. 1992. Cloning and domain structure of the mammalian splicing factor U2AF. Nature 355: 609-614.

Zuo, P. and J.L. Manley. 1993. Functional domains of the human splicing factor ASF/SF2. EMBO /. 12: 4727-4737. 


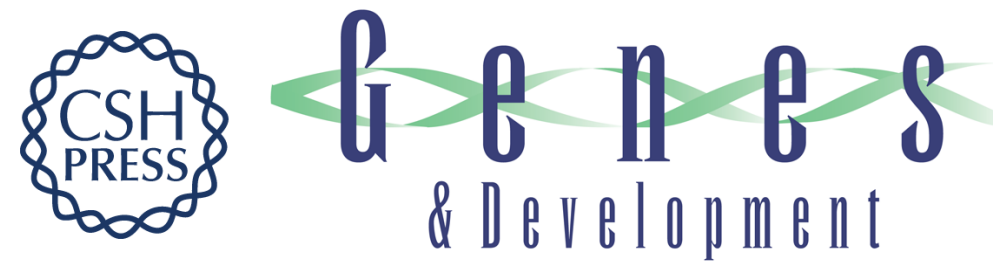

\section{A human RNA helicase-like protein, HRH1, facilitates nuclear export of spliced mRNA by releasing the RNA from the spliceosome.}

M Ohno and Y Shimura

Genes Dev. 1996, 10:

Access the most recent version at doi:10.1101/gad.10.8.997

References This article cites 37 articles, 6 of which can be accessed free at:

http://genesdev.cshlp.org/content/10/8/997.full.html\#ref-list-1

License

Email Alerting

Service

Receive free email alerts when new articles cite this article - sign up in the box at the top right corner of the article or click here.

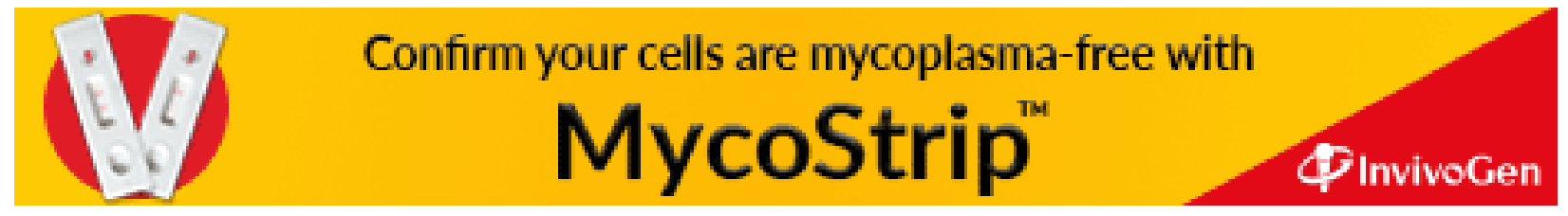

